\title{
Exploring national decarbonization pathways and global energy trade flows: a multi-scale analysis
}

Steve Pye ${ }^{1 *}$, Christophe McGlade ${ }^{1}$, Chris Bataille ${ }^{2,3}$, Gabrial Anandarajah $^{1}$, Amandine Denis-Ryan $^{4}$, and Vladimir Potashnikov 5

${ }^{1}$ UCL Energy Institute, University College London, 14 Upper Woburn Place, London, WC1H 0NN;

* Corresponding author e-mail: s.pye@ucl.ac.uk

2 l'Institut du Développement Durable et des Relations Internationales (IDDRI), 41 rue du Four, 75006 Paris, France;

${ }^{3}$ Energy and Materials Research Group (EMRG), School of Resource and Environmental Management, Simon Fraser University, Burnaby, British Columbia, V5A 1S6, Canada.

${ }^{4}$ ClimateWorks Australia, Level 16, 41 Exhibition St, Melbourne, Victoria, 3000, Australia.

${ }^{5}$ Russian Presidential Academy of National Economy and Public Administration (RANEPA), 82/5, Prospect Vernadskogo, Moscow, Russian Federation 119571.

\begin{abstract}
The role of fossils fuels in country economies will change radically over the next 40 years under a strong climate regime. Capturing this changing role through national-based analyses, however, is challenging due to the global nature of fossil fuel demand, and resulting trade patterns. This article sets out the limitations of existing national scale decarbonization analyses in adequately capturing global conditions, and explores how the introduction of a global modelling framework could provide vital insights, particularly for those countries dependent on fossil fuel exports or imports.
\end{abstract}

The article shows that fossil fuel use will significantly decline by 2050, although gas will have an important transition role. This leaves large fossil exporters exposed, the extent to which is determined by mitigation action in different regions, and particularly the pathways adopted by the larger Asian economies. We find that global scale models provide critical insights that complement the more detailed national analyses, and should play a stronger role in informing deep decarbonization pathways (DDPs). They also provide an important basis for exploring key uncertainties around technology uptake, mitigation rates and how this plays out in demand for fossil fuels. However, use of global models also calls for improved representation of country specifics in global models, which can overly simplify national economic and political realities. Using both model scales provides important insights that are complementary but which can challenge the other's orthodoxy. However, neither can replace the other's strengths.

\section{Policy relevance statement}

In recent years, how global fossil fuel markets evolve under different climate regimes has been subject to much debate and analysis. This debate includes whether investments in fossil fuel production still make sense or will be exposed in the future to liabilities associated with high carbon prices. This matters for Governments who need to develop coherent policy in relation to fossil fuel sectors, and their role as drivers of economic growth and in providing for domestic 
energy needs. This article argues that national analyses need to be fully cognisant of the globalscale transition, which can be informed by using a multi-scale modelling approach.

\section{Keywords}

Decarbonization, energy modelling scale, fossil fuel production, fossil fuel trade

\section{Acknowledgements}

The authors would like to acknowledge the funding provided by Children's Investment Fund Foundation (CIFF) under the DDPP project, and support from the EPSRC-funded wholeSEM project [EP/K039326/1], and by the Agence Nationale de la Recherche under the Investissements d'avenir programme [ANR-10-LABX-14-01].

\section{Introduction}

If the international community limits the increase in global average surface temperature to less than $2^{\circ} \mathrm{C}$, the share of fossil fuels in the energy mix will decrease rapidly over the next 35 years. The IEA recently estimated under its 2DS scenario that the share of fossil fuels in the primary energy mix would shrink from over $80 \%$ in 2012 to just over $40 \%$ in 2050 , with the coal share decreasing to around $10 \%$ (IEA, 2015).

This transition will drive changes in the global flows of fossil and non-fossil energy, with implications for energy producing countries, many of whom currently rely on such sectors for economic growth and development. The rate and scale of this change will be determined by the timing of the low carbon transition, technology development and choices (e.g. carbon capture and storage (CCS)), economic re-structuring and rates of growth, particularly in the larger markets of India and China.

The objective of this article is to explore how national-level decarbonization analyses represent this global shift, which could fundamentally influence the country transition due to changing markets reflected through commodity prices and availability. While it is self-evident that country analyses do make assumptions about a range of boundary conditions, the question is whether the approaches are sufficient. For example, for large fossil exporting countries, inadequate consideration of the global dimension risks overlooking potentially shrinking global markets, and underplaying macroeconomic effects.

We argue that a multi-scale modelling approach, combining country and global insights, could go some way to better informing mitigation analyses. National-scale analyses are crucial for representing decarbonization while accounting for country specifics, if indeed our longer term 
climate objectives are to be met (SDSN/IDDRI, 2015). However, use of a global framework allows the exploration via sensitivity analysis of how changing conditions for fossil fuel markets might affect national-scale analyses. Conversely, there is also the potential, through such multi-scale modelling, to better characterise regional or country-level specifics in global models, relating to technology deployment, socio-economic priorities, and political realities.

This multi-scale approach to mitigation analysis is tested. To do this, we consider the geographic differences between production of fossil resources using global modelling and national pathways, and try to determine why we observe differences. There are a range of potential reasons including: how scenarios are framed (e.g. use of different economic drivers); resource size and upfront and ongoing extraction costs; availability and deployment rate of key technologies; differing levels of upstream sector detail; marginal abatement costs; and recognition (or not) of political realities at both the global and national scale. Given the differences, we then consider the lessons for modelling at both scales, and the potential need for both approaches in Deep Decarbonization Pathway (DDP) analysis. This is an important gap in the literature, with few papers on insights from modelling at different scales, one exception being (Chen, Yin, \& Zhang, 2013).

We first consider, in section 2, how national decarbonization analyses have handled fossil trade and associated boundary conditions, in a review of the literature. Section 3 then describes the global modelling framework used, the scenario set-up and iteration undertaken with country teams participating in the Deep Decarbonization Pathways Project (DDPP). ${ }^{1}$ Section 4 presents the results of the global runs, and compares them to selected DDPP country analyses. Section 5 then concludes with key findings around modelling at different scales, and the implications for our understanding of the role of fossil fuels. It also highlights clear routes for further research.

\section{Capturing global fossil fuel market evolution in national decarbonization analyses}

The strengths of a national scale analysis are that it provides for detailed depiction of physical, market and policy aspects of a national system (Strachan, Pye, \& Hughes, 2008). However, they argue that a fuller account of international drivers on a system, such as resource

\footnotetext{
${ }^{1}$ The Deep Decarbonization Pathways Project (DDPP) is a collaborative global research initiative to understand how individual countries can transition to a low-carbon economy. National scale decarbonization analyses have been undertaken from 16 highest emitting countries, representing $74 \%$ of current global $\mathrm{CO}_{2}$ emissions from energy. www.deepdecarbonization.org.
} 
availability and price, should not be fixed exogenous assumptions but take account of the impact of regional or global mitigation policies. This reflects the profound changes envisaged in energy systems if $2^{\circ} \mathrm{C}$ compliant climate policies are effectively introduced.

In Table 1 we examine how recent decarbonization analyses take account of these external fossil fuel drivers (availability and price), and model energy trade. We focus our analysis on 'deep decarbonization' scenarios (consistent with the DDPP) characterised by a strong level of ambition in the longer term (>50\% reduction in reference to 1990/2010), capturing the main emissions sources, and crucially, based on contextually detailed national analyses. 
Table 1. Review of how national decarbonization analyses model global level energy issues including fossil fuel markets

\begin{tabular}{|c|c|c|c|}
\hline Country & Study reference & Model name / type & $\begin{array}{l}\text { Accounting for international drivers on national } \\
\text { systems, incl. fossil fuel markets }\end{array}$ \\
\hline $\begin{array}{l}\text { Canada / } \\
\text { China }\end{array}$ & $\begin{array}{l}\text { (Bataille, Tu, \& Jaccard, } \\
\text { 2008) }\end{array}$ & CIMS; Hybrid BU simulation & $\begin{array}{l}\text { Own price elasticities derived from estimated Armington } \\
\text { elasticities applied to end-use demands, including fossil } \\
\text { fuel commodities as final products. }\end{array}$ \\
\hline China & $\begin{array}{l}\text { (Chen, Wu, He, Gao, \& } \\
\mathrm{Xu}, 2007)\end{array}$ & $\begin{array}{l}\text { MARKAL; Hybrid BU } \\
\text { optimization }\end{array}$ & Not explicit in terms of global trade assumptions. \\
\hline China & $\begin{array}{l}\text { (Kejun, Qiang, Xing, \& } \\
\text { Xiulian, 2010) }\end{array}$ & $\begin{array}{l}\text { IPAC; Mixed framework: BU } \\
\text { + CGE + global IAM }\end{array}$ & $\begin{array}{l}\text { Global emissions models providing global system } \\
\text { dynamics, and a strong focus on technology learning. } \\
\text { Trade framework unclear, given CGE is typically } \\
\text { Armington, while global IAM is typically Heckscher- } \\
\text { Ohlin. }\end{array}$ \\
\hline France & $\begin{array}{l}\text { (Mathy, Fink, \& Bibas, } \\
\text { 2015) }\end{array}$ & IMACLIM-R; Hybrid CGE & Single region Armington approach \\
\hline France & (ADEME, 2012) & $\begin{array}{l}\text { Three-ME; Hybrid } \\
\text { multisector CGE }\end{array}$ & Single region Armington approach \\
\hline Germany & (Schmid \& Knopf, 2012) & REMIND-D; Hybrid CGE & Exogenous prices used for imported commodities. \\
\hline India & $\begin{array}{l}\text { (Shukla, Dhar, \& } \\
\text { Mahapatra, 2008) }\end{array}$ & $\begin{array}{l}\text { MARKAL/ AIM-CGE; } \\
\text { Mixed framework: BU } \\
\text { optimization + CGE }\end{array}$ & $\begin{array}{l}\text { Explicit representation via global AIM CGE; multi-region } \\
\text { Armington approach }\end{array}$ \\
\hline India & $\begin{array}{l}\text { (Shukla \& Chaturvedi, } \\
\text { 2012) }\end{array}$ & $\begin{array}{l}\text { GCAM-IIAM; IAM+ CGE } \\
\text { framework }\end{array}$ & $\begin{array}{l}\text { Heckscher-Ohlin non-spatial, net-trade; trade based on } \\
\text { relative factor endowments }\end{array}$ \\
\hline Ireland & $\begin{array}{l}\text { (Chiodi et al., 2013); } \\
\text { (Deane et al., 2013) }\end{array}$ & TIMES; B-U optimization & $\begin{array}{l}\text { Exogenous assumptions; commodity prices from IEA } \\
\text { WEO. }\end{array}$ \\
\hline Japan & (Fujino et al., 2008) & $\begin{array}{l}\text { PHM, BDM, TDM; Mixed } \\
\text { framework: BU + CGE }\end{array}$ & Single region Armington approach in CGE \\
\hline $\begin{array}{l}\text { South } \\
\text { Africa }\end{array}$ & (Winkler, 2007) & $\begin{array}{l}\text { LTMS; B-U optimization, } \\
\text { CGE }\end{array}$ & $\begin{array}{l}\text { Exogenous view of technology cost reductions / fuel } \\
\text { prices. Single region Armington in CGE. }\end{array}$ \\
\hline Switz. & $\begin{array}{l}\text { (Babonneau, Thalmann, \& } \\
\text { Vielle, 2015) }\end{array}$ & GEMINI; CGE & $\begin{array}{l}\text { Explicit multi-region Armington representation: } \\
\text { Switzerland, EU, USA, BRIC (Brazil, Russia, India and } \\
\text { China) and rest of the World. }\end{array}$ \\
\hline UK & $\begin{array}{l}\text { (Strachan, Pye, \& Kannan, } \\
\text { 2009) }\end{array}$ & $\begin{array}{l}\text { MARKAL-MACRO; B-U } \\
\text { optimization + CGE } \\
\text { extension }\end{array}$ & $\begin{array}{l}\text { Via sensitivity analysis, considers range of fossil prices, } \\
\text { opportunities for offsets, and resource availability }\end{array}$ \\
\hline UK & (Usher \& Strachan, 2012) & $\begin{array}{l}\text { MARKAL-Stochastic; B-U } \\
\text { optimization }\end{array}$ & $\begin{array}{l}\text { Exploration of boundary conditions (and respective } \\
\text { uncertainties) outside of decision maker control, namely } \\
\text { fossil fuel prices and bioenergy availability. }\end{array}$ \\
\hline UK & (Ekins et al., 2013) & MARKAL; B-U optimization & $\begin{array}{l}\text { Gas price sensitivity - and scenarios concerning resilience } \\
\text { of UK system. Also wider price sensitivities, and those } \\
\text { concerning bioenergy. }\end{array}$ \\
\hline UK & $\begin{array}{l}\text { (Pye, Sabio, \& Strachan, } \\
\text { 2015) }\end{array}$ & $\begin{array}{l}\text { ESME; B-U probabilistic } \\
\text { optimization }\end{array}$ & $\begin{array}{l}\text { Uncertainty across resource commodity price range, } \\
\text { bioenergy resource limits, and technology costs. }\end{array}$ \\
\hline USA & (Williams et al., 2012) & PATHWAY; Accounting & No representation; fixed exogenous assumptions. \\
\hline USA & $\begin{array}{l}\text { (McCollum, Yang, Yeh, \& } \\
\text { Ogden, 2012) }\end{array}$ & $\begin{array}{l}\text { CA-TIMES; B-U } \\
\text { optimization }\end{array}$ & No representation; fixed exogenous assumptions. \\
\hline USA & $\begin{array}{l}\text { (Paltsev, Reilly, Jacoby, \& } \\
\text { Morris, 2009) }\end{array}$ & $\begin{array}{l}\text { MIT-EPPA; Dynamic } \\
\text { recursive CGE }\end{array}$ & $\begin{array}{l}\text { Multiregional Armington (USA as one of several global } \\
\text { sectors). }\end{array}$ \\
\hline USA & $\begin{array}{l}\text { (Ross, Fawcett, \& Clapp, } \\
\text { 2009) }\end{array}$ & ADAGE; Regional CGE & $\begin{array}{l}\text { Other regions explicitly represented using the Armington } \\
\text { approach (Europe, BRIC, ROW, Other Annex I) }\end{array}$ \\
\hline USA & $\begin{array}{l}\text { (Tuladhar, Yuan, } \\
\text { Bernstein, Montgomery, \& } \\
\text { Smith, 2009) }\end{array}$ & $\begin{array}{l}\text { MRN and NEEM; Dynamic } \\
\text { CGE combined with BU } \\
\text { electricity sector. }\end{array}$ & $\begin{array}{l}\text { Multi-region for US, single region international } \\
\text { Armington approach in NEEM }\end{array}$ \\
\hline USA & (Goettle \& Fawcett, 2009) & IGEM; Dynamic CGE & $\begin{array}{l}\text { Single region Armington approach, normally used with } \\
\text { ADAGE, which has dedicated trade features. }\end{array}$ \\
\hline
\end{tabular}

There is a wide spread of approaches to capturing international fossil fuel factors (resource availability, prices and trade) in these country-based analyses. The Armington approach is the standard method used to consider trade in CGE analyses (Armington, 1969). An econometrically calculated elasticity, derived from historic trade data, is used to parameterize the sensitivity of trade relationships between countries for given commodity sets to changes in 
relative export and import prices. It can be used in a single stage with one region, or in two stages with multiple regions, each requiring its own elasticity (Lloyd and Zhang 2006). It is used to explain why seemingly identical commodities are not perfect substitutes, and are not all produced and exported from what seem to be the lowest cost production regions once freight costs are factored in, i.e. why are there preferential trade flows?

Like all econometrically-based approaches, however, the Armington's usability is limited to the plausible explanatory power of the range of data from which it is derived. As first articulated by (Griffin, 1977) for the energy modelling literature, past data are not useful for describing future phenomena if fundamental underlying conditions change. In the case where deep decarbonization is assumed, the characteristics of energy supply and demand technology could plausibly pass far out of the range of historical data (Laitner, DeCanio, Koomey, \& Sanstad, 2003), making use of the Armington assumption for fossil fuel commodities more a guessing game than econometric science.

Pure bottom-up (B-U) models tend to use exogenous production assumptions coupled with sensitivity analysis to account for uncertainty across international fossil fuel market assumptions. Some approach boundary condition uncertainty via sensitivity analyses, to understand the impact of high or low fossil prices (Strachan et al., 2009), or differing levels of bioenergy availability (Pye et al., 2015). Crucially, the national context and analysis priorities reflect the rigour in approach. For many of the high-import, low-export countries, it is not necessary to understand shifts in global demand and their implications on export markets; as price takers, however, sensitivity analysis around prices (and the evolution of technology costs) may be critical. Bottom-up hybrids like MARKAL MACRO/ED (Strachan et al., 2009) and CIMS (Bataille, Jaccard, Nyboer, \& Rivers, 2006) use own price elasticities to account for changes in demand driven by supply cost changes.

In summary, modelling approaches to capture the external fossil market and trade issues differ according to type of modelling approach. What is evident is that most rely heavily on contextspecific exogenous assumptions for external factors, because of perceived limited impact on analysis, or capacity constraints limit an improved analysis. There is evidently a role for global analyses to enhance the understanding at the national level, as we seek to demonstrate in the remainder of this article. 


\section{Methods}

To explore the role of fossil fuels in a $\mathrm{CO}_{2}$-constrained global system, we use a global energy system model, TIAM-UCL. This determines the trade flows of fossil commodities between producing and consuming regions, reflecting how demand drives production under climate and energy policy constraints. The model results provide a basis for comparison of fossil fuel production and supply with selected national pathways.

\subsection{National scale analysis under DDPP initiative}

Under the DDPP, national-scale decarbonization analyses, using a range of modelling approaches, have been developed by countries accounting for $74 \%$ of current global energybased emissions. $^{2}$ These provide the basis for exploring a multi-scale approach, and comparison with the global model output. The national pathways set out how deep decarbonization can be achieved by 2050 , through a range of emission reduction options. The concept of 'deep' means systems that, at the global level, have reduced annual emission levels to those commensurate with a $2^{\circ} \mathrm{C}$ pathway.

\subsection{Global modelling framework}

TIAM-UCL is an integrated assessment model, using the TIMES modelling platform ${ }^{3}$, which has been used to undertake numerous assessments of global low-carbon transitions pathways ((Anandarajah, McDowall, \& Ekins, 2013), (Kesicki \& Anandarajah, 2011), (McGlade \& Ekins, 2014)). It is a bottom-up, technology explicit framework, using linear programming to maximise total discounted social welfare under a range of techno-economic constraints. ${ }^{4}$ It is well-suited for exploring the role of fossil fuels and patterns of trade, representing all primary energy sources from resource production through to their conversion, infrastructure requirements, and sectoral end-use. The model is disaggregated into 16 regions. The base year is 2005 , with the full model run to 2100 , and the climate module to $2200 .^{5}$

It has a strong representation of the geographic distribution of fossil resources (McGlade \& Ekins, 2015), production capacities, and trade routes. The model satisfies consumption within each region by optimising the use of resources globally. In other words, it weighs the costs of producing domestically against the costs of supply from another region, including

\footnotetext{
${ }^{2}$ All country analyses can be found at www.deepdecarbonization.org.

${ }^{3}$ TIAM stands for TIMES Integrated Assessment Model.

${ }^{4}$ A global discount rate of $3.5 \%$ is used.

${ }^{5}$ Further information on input assumptions and supporting data sources can be found in (Anandarajah et al., 2011).
} 
infrastructure and additional transportation costs. ${ }^{6}$ Crude oil, oil products, gas (LNG and piped), coal and bioenergy can all be traded, as permitted trade routes and infrastructure allows. The model includes constraints on rates of extraction of resources, and those relating to sectoral demand, existing policies, and regional and global GHG reduction targets. ${ }^{7}$

\subsection{Representing national DDPs in a global model}

Scenarios were run in TIAM-UCL that allowed for comparison with country-based results, focussing on high fossil fuel exporting countries. The global scenarios included:

- $\quad T$-DDPP ('T' denoting TIAM-based scenario). A global $2^{\circ} \mathrm{C}$ scenario but with the national DDP mitigation strategies included, plus other country-based assumptions described below (Table 2).

- T-OPT. A reference $2^{\circ} \mathrm{C}$ TIAM run, to illustrate the cost-optimal allocation of mitigation action, in the absence of prescribed national action. This implies no need for transfer of carbon credits via trade as the optimal allocation is determined. Mitigation was permitted only from 2020 onwards, to represent near term policy inertia.

The primary basis for integrating DDPs into TIAM-UCL was by introducing national-scale carbon and carbon intensity of power generation constraints across model regions (see Table 2).

Table 2. Set-up of scenarios in TIAM-UCL

\begin{tabular}{|c|c|c|}
\hline Scenario change & Description & $\begin{array}{l}\text { Included in } \\
\text { scenario? }\end{array}$ \\
\hline $\begin{array}{l}\mathrm{CO}_{2} \text { emissions } \\
\text { reduction } \\
\text { trajectory }\end{array}$ & $\begin{array}{l}\text { DDP } \mathrm{CO}_{2} \text { reduction trajectories are represented as a fixed constraint where } \\
\text { there is a corresponding DDP-global model region match (10/16 } \\
\text { countries: Australia, Canada, China, India, Japan, Mexico, Russia, South } \\
\text { Korea, UK, and the USA). } \\
\text { In the absence of a DDP-global model match, the emissions reduction } \\
\text { ambition from a representative DDP country is used, e.g. the Brazil DDP } \\
\text { for the Central and South America (CSA) region. If no representative } \\
\text { DDP, it is assumed that countries converge on } 1.5 \mathrm{t} \mathrm{CO}_{2} / \text { capita in } 2050 \text {. } \\
\text { Because the global model accounts for } \mathrm{CO}_{2} \text { from industrial processes (e.g. } \\
\text { cement production) and from land use, land-use change and forestry, the } \\
\text { above trajectories were adjusted (if necessary) to include these emissions. }\end{array}$ & $\begin{array}{l}\text { T-DDPP } \\
\text { only }\end{array}$ \\
\hline $\begin{array}{l}\text { Carbon intensity } \\
\text { of power } \\
\text { generation }\end{array}$ & $\begin{array}{l}\text { DDP power generation carbon intensities were introduced for the years } \\
\text { 2020-2050, where a DDP-global model region match existed. }\end{array}$ & $\begin{array}{l}\text { T-DDPP } \\
\text { only }\end{array}$ \\
\hline Demand drivers & $\begin{array}{l}\text { GDP and population assumptions are based on SSP2, a central IPCC AR5 } \\
\text { scenario (O'Neill et al., 2014). This approach was taken to ensure } \\
\text { consistency of economic development at the global level, but means }\end{array}$ & All \\
\hline
\end{tabular}

\footnotetext{
${ }^{6}$ SI Figure 1 in Supplemental Information provides information on the commodity cost range of key traded fossil fuels.

${ }^{7}$ TIAM-UCL also models trade flows of bioenergy, including biofuels, and uranium.
} 


\begin{tabular}{|c|c|c|}
\hline & $\begin{array}{l}\text { economic drivers used can differ from DDP assumptions. This is } \\
\text { particularly the case for India. GDP growth } 2010-2050 \text { in SSP2 is equal to } \\
650 \% \text { compared with } \sim 1700 \% \text { in its DDP. While core driver assumptions } \\
\text { differ, the relationship between the drivers and resulting energy-service } \\
\text { demands (i.e. through demand elasticities), were based on the DDPs. }\end{array}$ & \\
\hline $\begin{array}{l}\text { Bioenergy w/ } \\
\text { CCS }\end{array}$ & $\begin{array}{l}\text { The deployment of CCS for fossil fuels is included in TIAM-UCL } \\
\text { (Anandarajah, Pye, Usher, Kesicki, \& Mcglade, 2011) and most country } \\
\text { DDPs, including India, China and USA. However, only the UK DDP } \\
\text { considered bioenergy with CCS, and therefore it was not used in TIAM- } \\
\text { UCL. }\end{array}$ & All \\
\hline $\mathrm{CO}_{2}$ trading & $\begin{array}{l}\mathrm{CO}_{2} \text { trading was not permitted between regions, ensuring that all } \\
\text { mitigation actions had to be taken within regions. } \\
\text { Trading does not occur in the T-OPT scenario as the mitigation effort is } \\
\text { optimally allocated in the absence of specified national targets. }\end{array}$ & $\begin{array}{l}\text { T-DDPP } \\
\text { only }\end{array}$ \\
\hline
\end{tabular}

In addition to the national $\mathrm{CO}_{2}$ emissions reduction trajectories, the climate module was used to ensure the global $2^{\circ} \mathrm{C}$ constraint is met. This captures the mitigation requirements across the main GHGs, not only $\mathrm{CO}_{2}$ but methane and nitrous oxide. This fits into the DDPP narrative, where the ambition in country analyses (plus comparable reductions in non-DDPP countries) limits global warming to less than $2^{\circ} \mathrm{C}$, based on the IPCC stated probability of exceeding $2^{\circ} \mathrm{C}$ in the 40-60\% range (Pachauri et al., 2014).

\section{Analysis of differences between modelling scales}

In this section, we present the results of the global model analysis, and comparison with country-specific analyses. Firstly, we establish the patterns of global fossil trade that emerge with and without the features of the DDPP country analyses. We then summarise the observations of the country teams, based on the comparison with their own analyses. Finally, we present the main insights from this model scale comparison. To ensure a focus on supply side transitions, we do not describe in detail mitigation action across the end use demand sectors.

\subsection{Global modelling results}

\subsubsection{Coal production and trade}

Under a $2^{\circ} \mathrm{C}$ constraint, of all fossil fuels, coal use is reduced the most; in T-DDPP, it reduces from $8000 \mathrm{Mt}$ of production per year, to just over $3000 \mathrm{Mt}$ by 2050 (Figure 1). By far the largest producer and consumer of coal is China, for power generation and industry. Production levels are steady to 2030, with a strong decline thereafter, while coal use in India remains stable throughout the time period, while falling steeply in terms of consumption per unit of economic 
output. The USA, the second largest producer, sees a rapid decline, with minimal production and use by 2030. Africa sees an increase in domestic production, driven by rapid economic growth. Of the total coal produced in 2010, only $15 \%$ is traded, reflecting that much domestic production is used in situ. By 2050, the absolute level of trade is approximately one-third of the trade level in 2010 , and $10 \%$ of the 2050 coal production level.

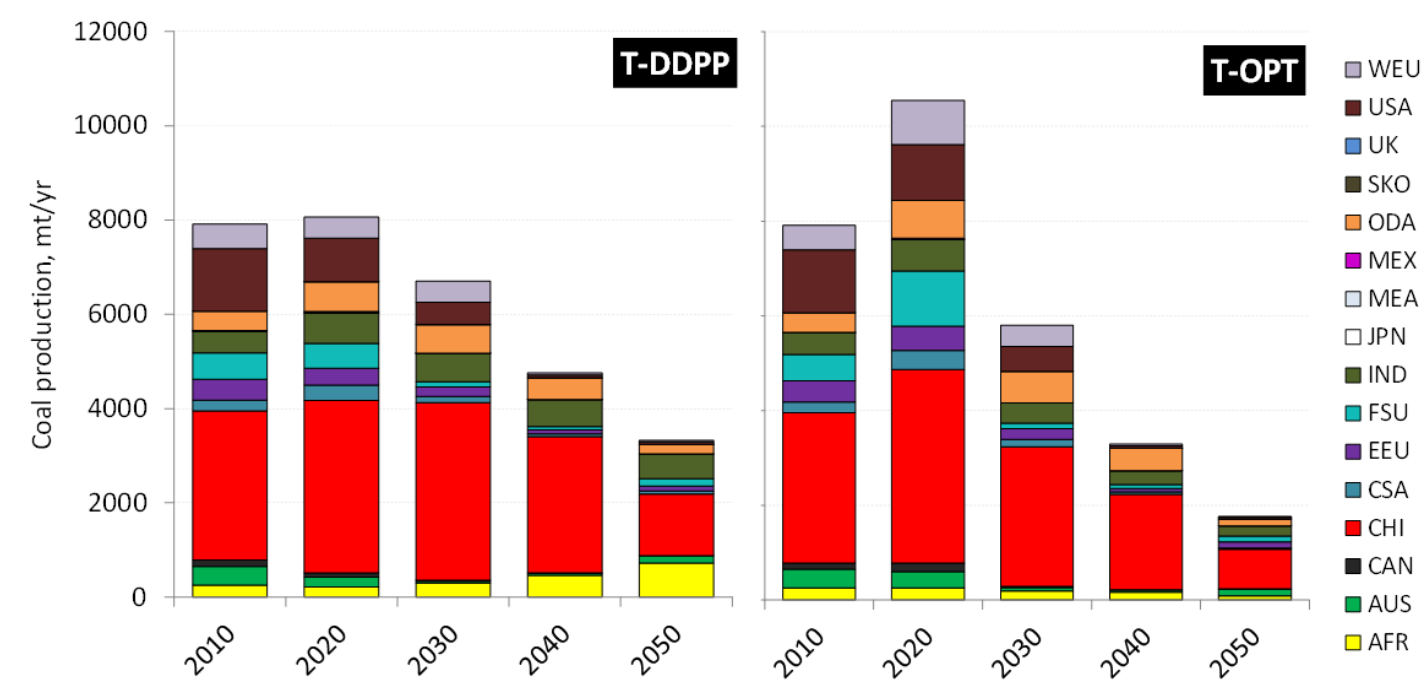

Figure 1. Global coal production by region ${ }^{8,9}$

The T-OPT case, where there is only a global emission limit, not region-specific targets, production falls to less than $2000 \mathrm{Mt}$ in 2050 . With the model optimising out to 2100, a more rapid decline reflects stronger mitigation prior to 2050 .

\subsubsection{Gas production and trade}

Globally, production increases $30-40 \%$ by 2050 relative to 2010 , providing an important lower carbon alternative to coal and oil, particularly to 2030 (as highlighted in (McGlade, Bradshaw, Anandarajah, Watson, \& Ekins, 2014)). T-OPT is at the higher end of this range, due to the more rapid removal of coal. While a similar pattern of production is seen under both scenarios, there is a marked regional difference in 2050 under T-DDPP, where domestic production in China increases, impacting on the production levels in export regions such as the Middle East

\footnotetext{
${ }^{8}$ Country abbreviations used in the graphs represent the following 16 regions: Africa (AFR), Australia (AUS), Canada (CAN), China (CHI), Central and Southern America (CSA), Eastern Europe (EEU), Former Soviet Union (FSU), India (IND), Japan (JPN), Middle East (MEA), Mexico (MEX), Other Developing Asia (ODA), South Korea (SKO), United Kingdom (UK), United States (USA) and Western Europe (WEU).

${ }^{9}$ The lower level in 2020 under T-OPT reflects limits on earlier mitigation under this scenario, as shown by higher levels of coal in 2020 .
} 
(MEA), the Former Soviet Union (FSU) and Australia (AUS), as compared to the T-OPT case. Africa, on the other hand, becomes a larger producer.
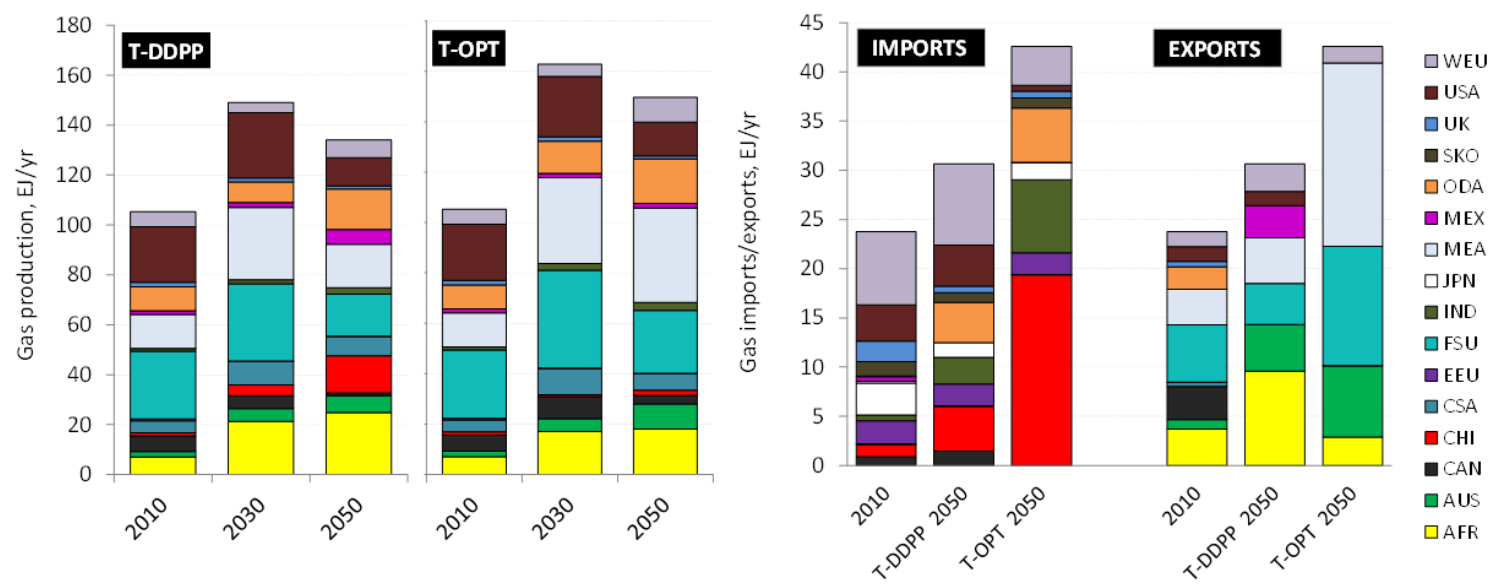

Figure 2. Global gas production by region (left), and gas imports \& exports by region (right)

Under T-DDPP, the level of trade is over $20 \%$ lower than observed under T-OPT. The shift to indigenous Chinese production under T-DDPP, reducing imports, highlights that a less stringent DDP reduction trajectory allows for additional emissions associated with domestic production. ${ }^{10}$ At the same time, a more stringent constraint on Middle East emissions (compared to T-OPT) impinges on the production levels in this export region. ${ }^{11}$ As such the regional distribution of mitigation impacts on the fossil fuel markets. The model is sensitive to such assumptions, and should therefore be viewed as a framework to test key uncertainties, in turn informing the range of boundary conditions for national analyses.

\subsubsection{Oil production and trade}

Oil production levels are approximately $25 \%$ lower in 2050 relative to 2010 , with the decline in oil consumption in the USA and other developed countries offsetting strong oil demand growth (due to rapid increases in mobility demand) in emerging economies of Africa, China and India. In 2050, consumption in these three regions (based on T-DDPP) is $51 \%$ of global demand, up from $15 \%$ in 2010. Under T-OPT, the share is around 35\%, reflecting the additional mitigation efforts in these regions, compared to T-DDPP. In both scenarios, the Middle East

\footnotetext{
10 See SI Figure 2 in the Supplemental Information for additional detail.

11 The constraint on Middle East emissions is the $1.5 \mathrm{tCO}_{2} /$ capita convergence level across non-DDPP countries, where no representative DDPP exists as an alternative basis for setting ambition levels. Clearly, future DDPs for countries in this large oil and gas producing region could potentially be less ambitious, in order to maintain a higher level of exports.
} 
remains the dominant producer, albeit at lower levels in 2050 under the T-DDPP scenario (compared to the T-OPT case).

\subsection{Comparison with national DDPs}

From the DDPP initiative, four of the major fossil producing regions participated in this analysis - Canada, USA, Australia and Russia. Each national team described how they considered trade in resources within their country analyses, as summarised in Table 3 . None used dedicated global modelling to inform the national system boundary conditions but were rather informed by a range of analyses.

Table 3. DDPP team approach to global fossil fuel trade issues

\begin{tabular}{|l|l|}
\hline Country team & Approach \\
\hline Australia & $\begin{array}{l}\text { CGE modelling uses inputs on expected global production volumes for key commodities, } \\
\text { and then calculates the likely production and exports coming from Australia based on costs } \\
\text { of production (impacted by decarbonization costs and exchange rates). Global production } \\
\text { volumes for coal, oil, and gas are based on the global DDPP parameters (aligned on IEA } \\
\text { WEO). }\end{array}$ \\
\hline Canada & $\begin{array}{l}\text { Three oil price scenarios were estimated, with the lowest price scenario (trending to } \\
\text { \$40/barrel in 2050) being used in this article. Output, GDP and trade effects were } \\
\text { estimated using the RGEEM regional CGE model (which explicitly includes a US model, } \\
\text { and therefore US demands and exports to Canada), based on cost of production and } \\
\text { following the Armington assumption for trade external to North America. Output volumes } \\
\text { were passed to the CIMS technology stock turnover simulation model, from which energy } \\
\text { and emissions volumes were calculated. }\end{array}$ \\
\hline Russia & $\begin{array}{l}\text { Combined with official oil and gas projections to 2030, strong consideration was given to } \\
\text { the possible evolution of different export sectors, particularly oil and gas, capturing both } \\
\text { resource potential, market evolution and political realities. }\end{array}$ \\
\hline USA & $\begin{array}{l}\text { The USA analysis treated fossil production sectors as having consistent levels of activity } \\
\text { under both Reference and DDPP scenarios. The purpose of this approach was reduce } \\
\text { exposure of the analysis to the criticism targets would only be met by curtailing economic } \\
\text { activity. }\end{array}$ \\
\hline
\end{tabular}

In the following section, country-based DDPP results (labelled 'DDP' below) are compared against the TIAM-UCL scenarios, taking account of country team comments.

\subsubsection{Australia}

In the Australia DDP, coal exports are at $60 \%$ of the 2010 level in 2050. The robust export level assumes an international market for coal, particularly for metallurgic processes, and the continued use of infrastructure assets. This outlook is broadly consistent with the aggregate global production levels under T-DDPP (Figure 1), where a decline to a 50\% level in 2050 is 
observed. The global model highlights a decline in the export market for coal, due to shift towards indigenous production in the large economies of China, India and Other Developing Asia (ODA).

With Australia accounting for 5\% of global production, and the three Asian regions accounting for $60 \%$ of consumption, a shift in to indigenous production by these regions can have a strong impact. In the global analysis, this impact on exports is observed between 2020 and 2040, with a strong decline in Australian exports, dropping to less than $20 \%$ of 2010 levels. Figure 3 does not show this decline, as export levels recover by 2050 due to rapidly falling domestic production in China; hence the 2050 levels under the global scenarios are higher than assumed in the DDP.

Two issues point the way to potential improvements in regional representation in global modelling. Firstly, TIAM-UCL only distinguishes between hard coal and lignite, an insufficient disaggregation to capture the important role of metallurgic exports, which account for half of Australian exports. Secondly, the feasibility of a rapid drop in coal exports to 2040 followed by an increase towards the end of the period is questionable, as this would necessitate the resurgence of a sector previously in long term decline. Both factors question the rapid decline in exports to 2040, and suggest a need for improved representation.
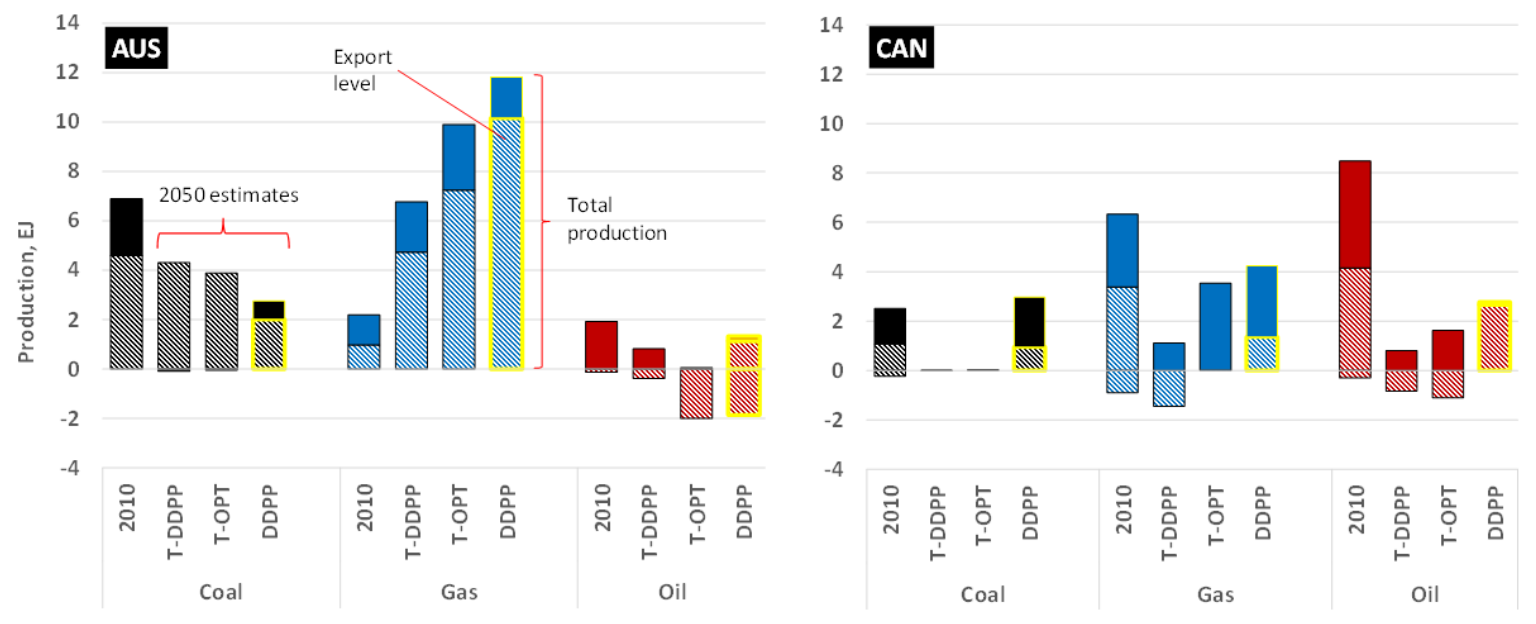

Figure 3. Production and import/exports in Australia / Canada under TIAM scenarios and DDPP estimates, 2010/2050

Notes on graphs: On the horizontal axis, 2010 is the base year from TIAM-UCL. T-DDPP / T-OPT represent 2050 values from TIAM-UCL, DDPP represents the 2050 value from the national pathway (bar with yellow border).

Bar height represents total domestic production, with patterned section the export share (greater than zero), or imports, where negative (less than zero). Domestic consumption can be estimated as total production less the export share plus any imports. 
To ensure consistency in comparison, the DDPP values are estimated by applying their 2010 / 2050 change to the TIAM-UCL base year (2010) value.

Both DDP and TIAM-UCL analyses suggest growing gas exports; in the DDP, the growth is more aligned to T-OPT, while T-DDPP is more conservative. T-OPT results from increasing import levels by China, and stronger growth in global gas demand, as discussed earlier. This reflects how markets can change given differing levels of regional mitigation action. Concerning oil, data limitations in both the global and national analysis make comparison problematic.

\subsection{2 $\underline{\text { Canada }}$}

For Canada, the TIAM-UCL scenarios show a decline in exports across all three fossil commodities out to 2050. For oil, this reflects a strong decline in US consumption, by far the largest export market. US import levels drop from 24 EJ in 2010 to 2-4 EJ in 2050; domestic Canadian production follows, reducing from 8.5 EJ in 2010 to 1-1.5 EJ in 2050 (Figure 3). Similar to oil, gas production declines strongly, particularly in T-DDPP, reflecting declines in lower cost conventional resources. Interestingly, higher prices, due to increased global demand under T-OPT sees domestic production hold firm, with a shift away from imports. Exports of coal show strong declines due to global demand reductions.

The DDP analysis provides some interesting alternative insights. For oil, the analysis considers three oil price scenarios, with only the low $\$ 40$ per barrel case following a similar trend to that under the global analysis. The higher price scenarios assume global markets with prices in the range of $\$ 80-110$, allowing for production levels to be maintained (at $\$ 80$ ) or grow (at $\$ 110$ ) out to 2050. From the global perspective, there is a question as to whether such a price would be supported in the long term under a $2^{\circ} \mathrm{C}$ scenario. The DDP also allows for efficiency gains in operating costs, direct emissions reduction through process and CCS changes, and lower production costs across assets that have already been paid for. However, the global analysis highlights that, were Canada to remain tied to the US markets (other markets could be sought in the future), prospects for any moderate production level would be poor given rapidly falling transport fossil fuel demand.

By 2050, gas production levels have declined in both analysis scales, with similar levels of domestic consumption. Under the global analysis, Canada is no longer an exporter of gas, reflecting a depleted resource base, particularly for the lower cost conventional resources. While a net importer under T-DDPP, a stronger demand for gas and higher prices under T-OPT 
see exploitation of higher cost gas resources to meets domestic needs. The DDP analysis see production levels maintained at $70 \%$ of 2010 levels, with a share of production still being exported. This analysis assumes longevity in current exploited fields due to enhanced drilling techniques, and additional exploitation of higher cost reserves in the Northwest Territories and north-east British Columbia, offsetting any declines in currently exploited basins.

For coal, the DDP analysis assumes metallurgical coal exports remain stable in the long term i.e. are at the same level in 2050 as in 2010 . As discussed above, this trend is not observed in the global analysis, due to market shrinkage under strong climate constraints. As stated earlier, the global model representation of coal types is limited.

\subsubsection{Russia}

Reflecting an obvious challenge with model scale comparison, the global model results are for the Former Soviet Union (FSU), making the comparison with the Russian DDP analysis somewhat problematic, particularly as some of the post-Soviet states are large energy exporters (Kazakhstan) and consumers (Ukraine). Therefore, insights are strongly caveated.

The most significant fossil export commodity is gas; in TIAM-UCL, the FSU region accounts for over a quarter of global production, and takes a similar share of the export market. Gas exports are estimated to rise to 2020 , followed by a gradual reduction to 2050 , where exports are between $60 \%$ (T-DDPP) and 90\% (T-OPT) of the 2010 level. The continuation of significant exports in both cases reflects sustained use of gas in the European market; under TDDPP, the decline reflects the expansion of new sources of gas, including from Africa, as well as a slow decline in global consumption levels.

The DDP analysis put exports in the range of the global model results, the level reflecting robust reserve estimates, the political decision to continue exploiting gas resources, cost reductions due to increasing production by independent producers, and new markets for gas via LNG exports. Other countries in the FSU region not captured in the DDP that could have a strong impact on gas supply include Turkmenistan (with the fourth largest proven natural gas reserves globally) and Kazakhstan.

Oil production shows a strong decline, and is estimated to be $50 \%$ of the 2010 level under TDDPP, and 25\% under T-OPT, due to stronger mitigation action. The country DDP shows a similar level of decline in production as T-DDPP, and export share in 2050. Under the DDP, 
exports halve by 2050, based on a much higher export share in 2010 than shown in Figure 4. This highlights the difficulty of comparing these quite different model regions.

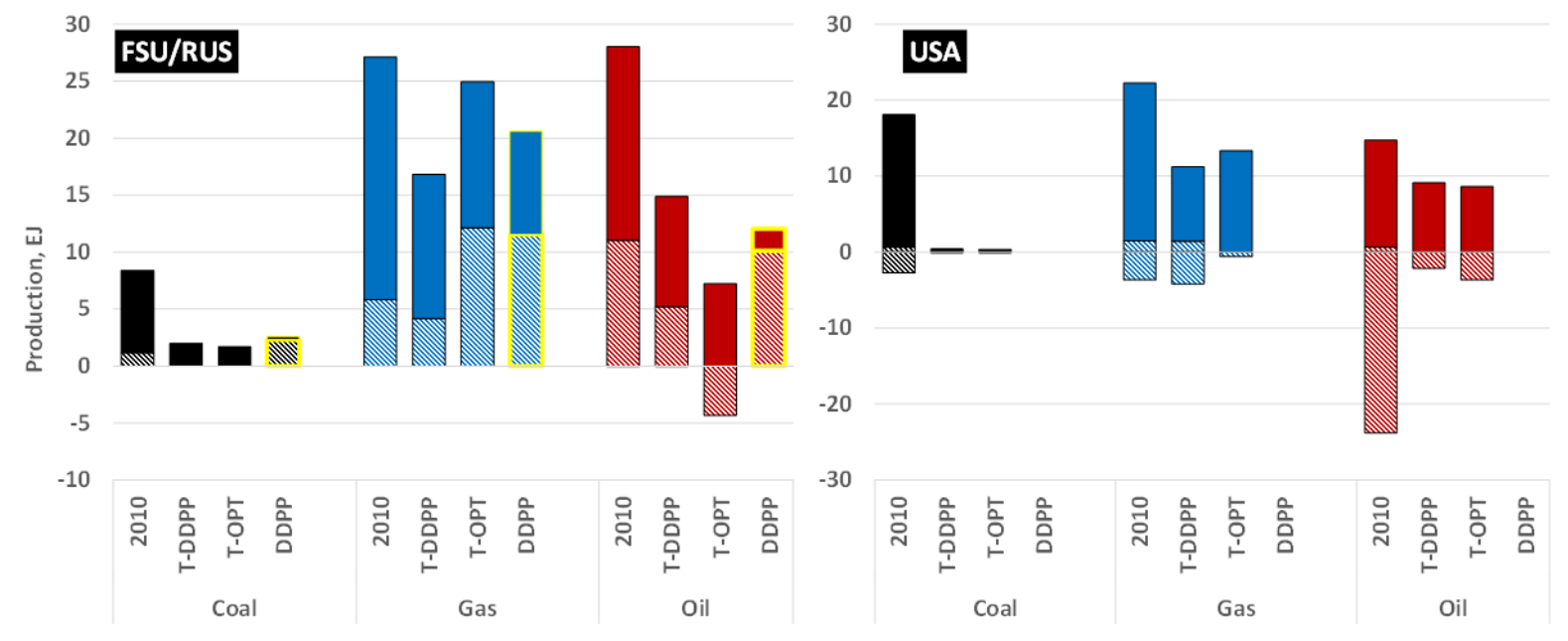

Notes on graphs: see Figure 3. For USA, no trade assumptions were available in country analysis so production data are omitted from 'DDPP' series

Figure 4. Production and import/exports in Russia / USA under TIAM scenarios and DDPP estimates, $2010 / 2050$

Coal exports are maintained in the DDP analysis, while dropping off to zero by 2030 in the global modelling. This small level of exports could potentially be explained by Russia exporting to other FSU countries, which of course would not be observable in the global analysis.

\subsubsection{USA}

The global modelling suggests, like the country-based assessment, that the USA radically reduces its consumption of all fossil commodities. Relative to 2010, domestic consumption of coal, oil and gas in 2050 reduces by $97 \%, 60-70 \%$ and $43 \%$ respectively. These changes in demand have a dramatic effect on oil imports in particular (Figure 4), as reflected in Canadian exports. For gas, while production declines, the net import-exports are the same under T-DDPP while under T-OPT, there is almost no trade.

In the USA analysis, no explicit representation of trade was made; rather domestic production levels were kept broadly constant in spite of declining demand. The implicit assumption in holding levels constant is that excess domestic production might feed into export markets. The global analysis suggests otherwise. Maintaining production levels in the DDP analysis was to avoid the conclusion that mitigation can only be achieved at the expense of energy production sectors. This type of stakeholder perception issue is of course crucial in the process of 
engagement on deep decarbonization. However, further analysis of the impacts of a decline in production is warranted for two reasons; firstly, from a technical mitigation perspective, national emission reduction levels could be achievable at lower cost, but secondly, this inevitably would lead to economic impacts on these production sectors.

\subsection{Key insights from model scale comparison}

This comparison exercise brings two key insights; firstly, national models cannot easily capture the changing patterns of trade in a global system, which can vary significantly depending on assumptions. Secondly, global models such as TIAM-UCL can omit some key specific features of national systems, a level of detail that can be critical in determining the role of fossil fuels.

The global model highlights that regional allocation and timing of mitigation ambition can significantly change patterns of trade for fossil fuels. For example, stronger early action increases the role (and price) of gas and reduces that of coal. Another key insight is that even small shifts in fuel production and use in high demand regions can have a strong impact on trade flows. Finally, there are large uncertainties in the global system, which are difficult to understand outside of a global framework.

There are equally important corresponding insights from the detailed characterisation of national-scale analyses. Firstly, the economics of fossil production are better represented in terms of sunk investment, the viability of production at different market prices, exchange rate fluctuations, and other economic drivers. Such factors can provide inertia to the transition that a cost-optimising model cannot fully capture. Secondly, national analyses can provide a more detailed level of the technological representation of demand and supply mitigation options. Taken together with the importance of political factors (e.g. safeguarding or promoting industries), this additional detail can provide an alternative outlook on the prospects for fossil production industries under stringent climate constraints.

There are of course key challenges with this type of model scale comparison. Country-scale analyses typically do not match the regional disaggregation applied in global models. The example of Russia and the FSU is a key example; to improve global modelling of fossil fuels, key FSU countries should be considered for explicit representation. On the other hand, a balance must be struck between disaggregation and tractability. Having these divergent outlooks and associated insights based on different scales should be seen as a strength. These differences should be treated openly and directly, at minimum through simple sensitivity analysis. 


\section{Conclusions and recommendations}

This article explores the role of fossil fuels in a decarbonized future under different modelling scales. At the global level, our analysis suggests that fossil fuels do still play a role in deeply decarbonised systems. However, large exporting countries need to be cognisant of substantial reductions in future years, the rate of which will be determined by the distribution and rate of mitigation (particularly in the larger economies), technology commercialisation and uptake (e.g. the role of process changes and CCS), and shifts towards indigenous production. Otherwise there is a danger that national models for such countries will assume unrealistic global markets for their energy products.

Key uncertainties are evident in the system, across the factors mentioned above. Furthermore, there appears to be limited recognition of these factors in a robust and systematic way in many national analyses, highlighting a role for global frameworks. This is important given our national analyses which, in part, highlight a tendency to overestimate the role of fossil production sectors and level of exports. However, we also conclude that increased use of global models to inform national analyses requires better representation of national systems, such as policy priorities (energy security, support for industry), operational economics, and improvements to representation of specific fossil resources and their use in different regions.

While the global modelling illustrates changes in patterns of production and trade, it does not capture the large macro-economic effects that will result. Further work is needed to explore these wider economy implications, and what this means for economic development, as was considered in detail in the Canada case study. This will increase the potential use and insights for informing national DDPs.

To summarise, both model scales provide important insights that are complementary while sometimes challenging the other's orthodoxy. However, neither can replace the other; while global modelling, as described in this article, provides the consistency of ensuring supplydemand balance and inter-regional commodity flows, it does not capture some of the detailed level techno-economic characteristics of production sectors in national analyses, nor the specific policy priorities. This reflects both the additional information that comes from national expertise, and the need to keep the global model tractable, and therefore to some extent aggregated. 
Following COP21, and the urgent need for countries to develop national DDPs, a move towards more multi-scale analyses could be an important means of providing a more robust understanding of how international drivers of fossil trade under decarbonization may impact on the domestic strategy. These insights will be of relevance to policy makers planning domestic policy exposed to international factors, with impacts on energy costs, security and exports. This is not only applicable to fossil trade but also to other global boundary assumptions, including technology costs, bioenergy resources and carbon prices (if regional or global pricing schemes are assumed). Clearly there are capacity constraints on global modelling teams, and therefore collaboration via different networks, including the DDPP, should be encouraged and explored.

\section{References}

ADEME. (2012). L'évaluation macroéconomique des visions énergétiques 2030-2050 de l'ADEME. Retrieved from http://www.ademe.fr/sites/default/files/assets/documents/evaluation-macroeconomiquevisions-energetiques-2030-2050-med00090136.pdf

Anandarajah, G., McDowall, W., \& Ekins, P. (2013). Decarbonising road transport with hydrogen and electricity: Long term global technology learning scenarios. International Journal of Hydrogen Energy, 38(8), 3419-3432. http://doi.org/10.1016/j.ijhydene.2012.12.110

Anandarajah, G., Pye, S., Usher, W., Kesicki, F., \& Mcglade, C. (2011). TIAM-UCL Global model documentation. UCL. Retrieved from http://www.ucl.ac.uk/energymodels/models/tiam-ucl/

Armington, P. S. (1969). A Theory of Demand for Products Distinguished by Place of Production (Une théorie de la demande de produits différenciés d'après leur origine)(Una teoría de la demanda de productos distinguiéndolos según el lugar de producción). Staff Papers-International Monetary Fund, 159-178.

Babonneau, F. L. F., Thalmann, P., \& Vielle, M. (2015). Defining deep decarbonization pathways for Switzerland: An economic evaluation based on the computable general equilibrium model GEMINI-E3. In 18th Annual Conference on Global Economic Analysis.

Bataille, C., Jaccard, M., Nyboer, J., \& Rivers, N. (2006). Towards general equilibrium in a technology-rich model with empirically estimated behavioral parameters. Energy Journal, 27(SPEC. ISS. OCT.), 98-112. Retrieved from http://www.scopus.com/inward/record.url?eid=2-s2.0$50549089991 \&$ partnerID=40\&md5=4c99ac429146950859994cdb73df09c8

Bataille, C., Tu, J., \& Jaccard, M. (2008). Permit sellers, permit buyers: China and Canada's roles in a global low-carbon society. Climate Policy. http://doi.org/10.3763/cpol.2007.0494

Chen, W., Wu, Z., He, J., Gao, P., \& Xu, S. (2007). Carbon emission control strategies for 
China: A comparative study with partial and general equilibrium versions of the China MARKAL model. Energy, 32(1), 59-72. http://doi.org/10.1016/j.energy.2006.01.018

Chen, W., Yin, X., \& Zhang, H. (2013). Towards low carbon development in China: a comparison of national and global models. Climatic Change, 1-14.

Chiodi, A., Gargiulo, M., Rogan, F., Deane, J. P., Lavigne, D., Rout, U. K., \& Ó Gallachóir, B. P. (2013). Modelling the impacts of challenging 2050 European climate mitigation targets on Ireland's energy system. Energy Policy, 53, 169-189. http://doi.org/10.1016/j.enpol.2012.10.045

Deane et al. (2013). Low Carbon Energy Roadmap for Ireland. Retrieved from http://www.environ.ie/en/Publications/Environment/ClimateChange/FileDownLoad,417 27,en.pdf

Ekins, P., Keppo, I., Skea, J., Strachan, N., Usher, W., \& Anandarajah, G. (2013). The UK energy system in 2050: comparing low-carbon, resilient scenarios. UK Energy Research Centre.

Fujino, J., Hibino, G., Ehara, T., Matsuoka, Y., Masui, T., \& Kainuma, M. (2008). Backcasting analysis for $70 \%$ emission reduction in Japan by 2050. Climate Policy. http://doi.org/10.3763/cpol.2007.0491

Goettle, R. J., \& Fawcett, A. A. (2009). The structural effects of cap and trade climate policy. Energy Economics, 31(SUPPL. 2). http://doi.org/10.1016/j.eneco.2009.06.016

Griffin, J. M. (1977). The econometrics of joint production: another approach. The Review of Economics and Statistics, 389-397.

IEA. (2015). Energy Technology Perspectives 2015 - Mobilising Innovation to Accelerate Climate Action. Paris.

Kejun, J., Qiang, L., Xing, Z., \& Xiulian, H. (2010). Technology roadmap for low carbon society in China. Journal of Renewable and Sustainable Energy, 2(3), 31008.

Kesicki, F., \& Anandarajah, G. (2011). The role of energy-service demand reduction in global climate change mitigation: Combining energy modelling and decomposition analysis. Energy Policy, 39(11), 7224-7233.

Laitner, J. A., DeCanio, S. J., Koomey, J. G., \& Sanstad, A. H. (2003). Room for improvement: Increasing the value of energy modeling for policy analysis. Utilities Policy, 11(2), 87-94. http://doi.org/10.1016/S0957-1787(03)00020-1

Mathy, S., Fink, M., \& Bibas, R. (2015). Rethinking the role of scenarios: Participatory scripting of low-carbon scenarios for France. Energy Policy, 77, 176-190.

McCollum, D., Yang, C., Yeh, S., \& Ogden, J. (2012). Deep greenhouse gas reduction scenarios for California - Strategic implications from the CA-TIMES energy-economic systems model. Energy Strategy Reviews, 1(1), 19-32. http://doi.org/10.1016/j.esr.2011.12.003

McGlade, C., Bradshaw, M., Anandarajah, G., Watson, J., \& Ekins, P. (2014). A Bridge to a Low-Carbon Future? Modelling the Long-Term Global Potential of Natural Gas. UKERC Research Report.

McGlade, C., \& Ekins, P. (2014). Un-burnable oil: An examination of oil resource utilisation in a decarbonised energy system. Energy Policy, 64, 102-112. 
http://doi.org/10.1016/j.enpol.2013.09.042

McGlade, C., \& Ekins, P. (2015). The geographical distribution of fossil fuels unused when limiting global warming to 2 [deg] C. Nature, 517(7533), 187-190.

O’Neill, B. C., Kriegler, E., Riahi, K., Ebi, K. L., Hallegatte, S., Carter, T. R., ... van Vuuren, D. P. (2014). A new scenario framework for climate change research: the concept of shared socioeconomic pathways. Climatic Change, 122(3), 387-400.

Pachauri, R. K., Allen, M. R., Barros, V. R., Broome, J., Cramer, W., Christ, R., ... Dasgupta, P. (2014). Climate Change 2014: Synthesis Report. Contribution of Working Groups I, II and III to the Fifth Assessment Report of the Intergovernmental Panel on Climate Change.

Paltsev, S., Reilly, J. M., Jacoby, H. D., \& Morris, J. F. (2009). The cost of climate policy in the United States. Energy Economics, 31(SUPPL. 2). http://doi.org/10.1016/j.eneco.2009.06.005

Pye, S., Sabio, N., \& Strachan, N. (2015). An integrated systematic analysis of uncertainties in UK energy transition pathways. Energy Policy.

Ross, M. T., Fawcett, A. A., \& Clapp, C. S. (2009). U.S. climate mitigation pathways post2012: Transition scenarios in ADAGE. Energy Economics, 31(SUPPL. 2). http://doi.org/10.1016/j.eneco.2009.06.002

Schmid, E., \& Knopf, B. (2012). Ambitious mitigation scenarios for Germany: A participatory approach. Energy Policy, 51, 662-672.

SDSN/IDDRI. (2015). Pathways to Deep Decarbonization. Retrieved from http://deepdecarbonization.org/wp-content/uploads/2015/06/DDPP_EXESUM.pdf

Shukla, P., \& Chaturvedi, V. (2012). Low carbon and clean energy scenarios for India: Analysis of targets approach. Energy Economics, 34(SUPPL. 3). http://doi.org/10.1016/j.eneco.2012.05.002

Shukla, P., Dhar, S., \& Mahapatra, D. (2008). Low-carbon society scenarios for India. Climate Policy. http://doi.org/10.3763/cpol.2007.0498

Strachan, N., Pye, S., \& Hughes, N. (2008). The role of international drivers on UK scenarios of a low-carbon society. Climate Policy, 8(1), 125-139. Retrieved from http://discovery.ucl.ac.uk/170052/

Strachan, N., Pye, S., \& Kannan, R. (2009). The iterative contribution and relevance of modelling to UK energy policy. Energy Policy, 37(3), 850-860. Retrieved from http://discovery.ucl.ac.uk/170049/

Tuladhar, S. D., Yuan, M., Bernstein, P., Montgomery, W. D., \& Smith, A. (2009). A topdown bottom-up modeling approach to climate change policy analysis. Energy Economics, 31(SUPPL. 2). http://doi.org/10.1016/j.eneco.2009.07.007

Usher, W., \& Strachan, N. (2012). Critical mid-term uncertainties in long-term decarbonisation pathways. Energy Policy, 41, 433-444. http://doi.org/10.1016/j.enpol.2011.11.004

Williams, J. H., DeBenedictis, A., Ghanadan, R., Mahone, A., Moore, J., Morrow, W. R., ... Torn, M. S. (2012). The Technology Path to Deep Greenhouse Gas Emissions Cuts by 2050: The Pivotal Role of Electricity. Science. http://doi.org/10.1126/science.1208365 
Winkler, H. (2007). Long term mitigation scenarios. Project Report, Energy Research Center, University of Cape Town. 